\title{
THE ROLE OF ONTOGENETIC DEVELOPMENT IN FISH SCALE SHAPE CHANGES
}

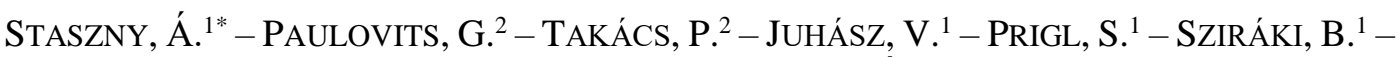 \\ URBÁNYI, B. ${ }^{1}-$ FERINCZ, Á. ${ }^{1}$ \\ ${ }^{1}$ Department of Aquaculture, Szent István University \\ Páter Károly str. 1, H-2100 Gödöllö, Hungary \\ ${ }^{2}$ Balaton Limnological Institute, Hungarian Academy of Sciences \\ Klebelsberg Kuno str. 3, H-8237 Tihany, Hungary \\ *Corresponding author \\ e-mail: Staszny.Adam@mkk.szie.hu; phone:+36-70-395-0905; fax: +36-28-522-927 \\ (Received $12^{\text {th }}$ Nov 2018; accepted $4^{\text {th }}$ Feb 2019)
}

\begin{abstract}
Fish scale investigation has been used in many ways. Recently several species' scale shape was used to differentiate species, populations or stocks. Effects of allometric growth on scale shape proved to be a common phenomenon in case of numerous species, however there is no information regarding the impact of temporal (ontogenetic timescale) changes. In this study the effect of intrapopulation age distribution on the scale shape was tested. Seven age groups of a gibel carp (Carassius gibelio) population were identified and analyzed using landmark-based geometric morphometric methods. The results indicated a clear trend of ontogenetic-driven shape change of gibel carp scales: the adult fish specific scale shape occurs at the age of $3+$, along with sexual maturation, the alterations among the older age classes show no significant differences. These results suggest that the asymmetric age distribution of fish populations should be taken into consideration during scale morphometric analyses.
\end{abstract}

Keywords: geometric morphometrics, shape analysis, allometry, Carassius gibelio, age

\section{Introduction}

Increasing number of papers reported the usefulness of morphometrical studies of fish scale shape (Avigliano et al., 2017; Ibanez and Jawad, 2018; Albertson et al., 2018). The methodology has numerous advantages in fish population studies (e.g. cheap, fast), however more precise assessment of application conditions are necessary. Previous studies described that allometric growth has to be taken into consideration during scale shape analyses (Ibáñez et al., 2012; Staszny et al., 2012.), however the correlations of the specimens' age and scale shape were neither considered, nor studied yet. The correlation between the age and body shape was proved in the case of fish (Wimberger, 1992), and similar patterns were observed in wide taxonomical range, e.g. in case of the human ribcage (Gayzik et al., 2008) or the wing shape of Blackcaps (Sylvia atricapilla Linnaeus, 1758) (Pérez-Tris and Tellería, 2001).

As an easily conductible, well-repeatable, non-destructive method, fish scale shape related analyses might emerge importance in various ecological studies (Takács et al., 2016); therefore, assessment of the source of shape variability within a studied group is crucial. The aim of our study was to test the effect of within-population age distribution on scale morphometric analyses, in order to assess the presence of ontogenetic changes in scale shape. 


\section{Review of literature}

Answers can be found for many population level questions, encoded in fish scales. Generally, fish scales are used in taxonomy in species identification (e.g. in case of gut content analyses of Piscivores (Bräger et al., 2016)), also used in population level separations (as a cheaper alternative of population genetic methods) (Ibáñez et al., 2007; Garduño-Paz et al., 2010; Staszny et al., 2012; Ibáñez, 2015) and species separation (Șerban and Grigoraş, 2018). It is suitable for age determination and for the backcalculation of individual- or population-level growth in temperate climate zone (Pompei et al., 2011; Soriguer et al., 2000). Similarly to other body parts, the phenotype of scales is affected by genetic, environmental and their covariate effects, during the lifespan of the fish (Ibáñez et al., 2012; Staszny et al., 2013). This phenomenon is partially confirmed by the study of Garduño-Paz et al. (2010), which successfully discriminated sympatric ecotypes of Arctic charr (Salvelinus alpinus Linnaeus, 1758) within Loch Tay lake and Loch Awe lake, based on their scale shape.

\section{Materials and methods}

Fish samples were collected during the summer of 2011 from the littoral zone of the Kis-Balaton Water Quality Protection System (Hungary, Coordinates N46.657537 E 17.194324) (Fig. 1), using a battery-powered electric fishing device (SAMUS 725MP).

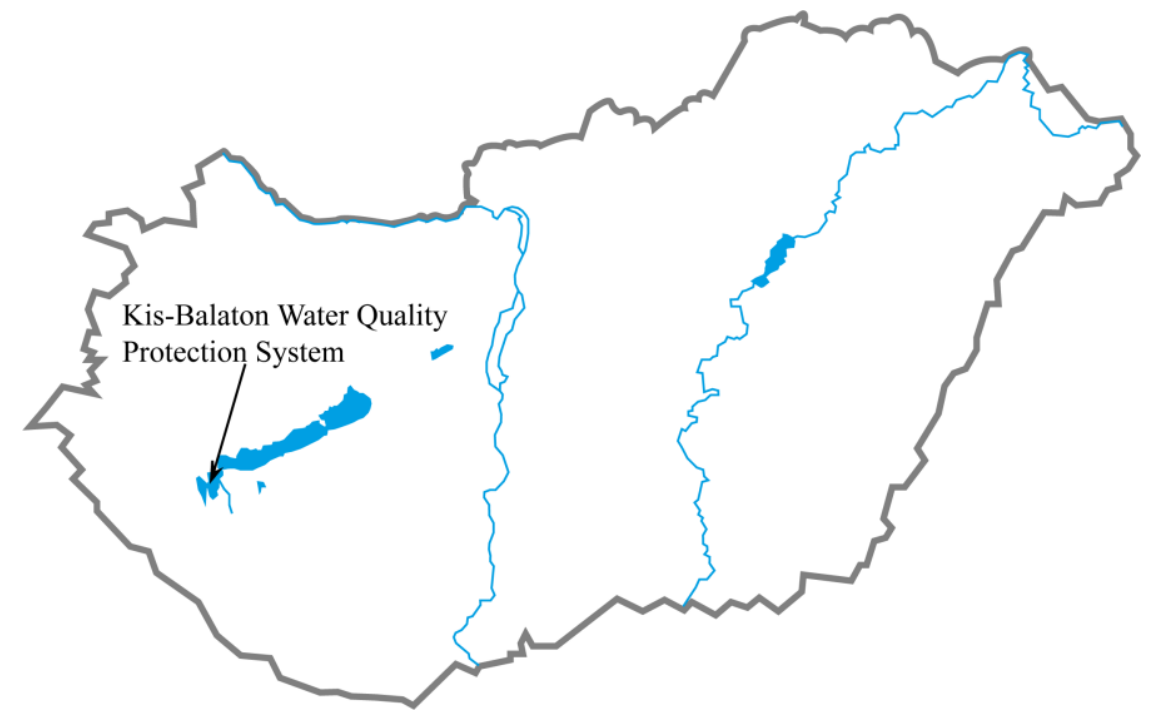

Figure 1. The sampling area of the study

The non-indigenous Cyprinid gibel carp (Carassius gibelio Bloch, 1782) was selected as model species. Scale samples (one per specimen) were collected from the flank, anterior to the dorsal fin (Garduño-Paz et al., 2010), from the left side of the body in order to avoid the variance caused by the fluctuating asymmetry (Sheridan and Pomiankowski, 1997). Scales were then placed between two glass slides and digitalized by using a HP ScanJet 5300C XPA scanner at 2400 dpi (upper lighting). Altogether 273 gibel carp specimens were collected. The age of each fish was determined based on the number of annual rings, determined based on the digital images by the same expert. Seven experimental groups were created using the scales of randomly selected 20-20 
specimens from age groups of $0+-6+$, where $0+$ stands for young-of-the-year individuals and $6+$ represents seven year-old fish. The average standard length and weights of the age groups are shown in Table 1.

Table 1. Average standard length ( $\mathrm{mm})$ and weights $(\mathrm{g})$ of the age groups

\begin{tabular}{c|c|c}
\hline Age group & Weight $(\mathbf{g})$ & Standard length $(\mathbf{m m})$ \\
\hline $0+$ & $30.18 \pm 19.41$ & $89.27 \pm 29.02$ \\
$1+$ & $35 \pm 11.98$ & $101.06 \pm 12.52$ \\
$2+$ & $119 \pm 51.98$ & $146.67 \pm 23.23$ \\
$3+$ & $289.67 \pm 66.23$ & $205.5 \pm 17.73$ \\
$4+$ & $411.92 \pm 57.07$ & $234.54 \pm 12.55$ \\
$5+$ & $586.67 \pm 111.35$ & $257.89 \pm 17.93$ \\
$6+$ & $790.67 \pm 60.74$ & $287.17 \pm 10.74$ \\
\hline
\end{tabular}

Shape was analysed by using landmark-based geometric morphometric methods (Zelditch et al., 2004). Seven easily definable landmarks (Ibáñez et al., 2007) were recorded on each scale by using tpsUtil (Rohlf, 2015) and tpsDig2 (Rohlf, 2005) software (Fig. 2). Landmarks 1 and 3 are the ventro- and dorso-lateral tips of the anterior portion of the scale. Landmarks 4 and 6 are at the boundary between the area covered by other scales and the exposed area, landmark 7 is positioned at the tip of the posterior portion of the scale. Landmark 2 is in the center of the anterior edge of the scale, and landmark 5 is the focus of the scale.

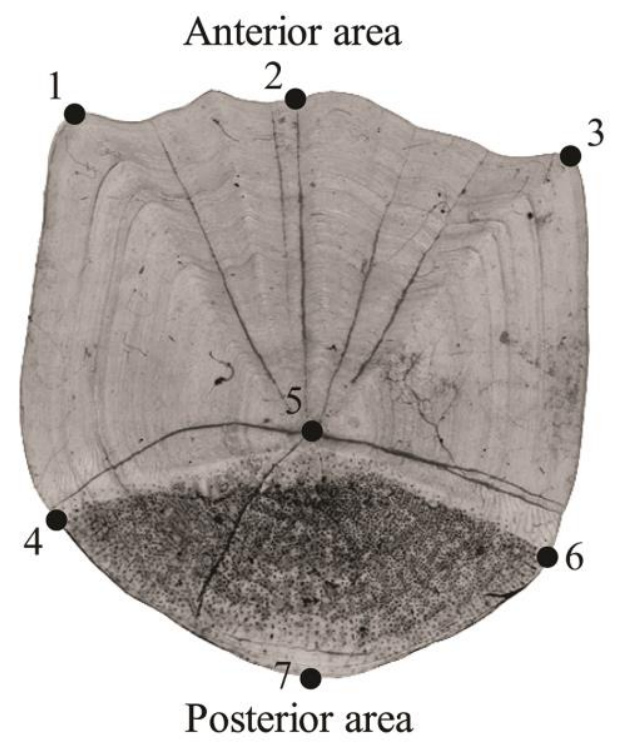

Figure 2. Landmarks used to define the shape of the scales. The areas of the scales are described with respect to the fish position

MorphoJ software package was used for further multivariate analysis (Klingenberg, 2011). Generalized least-squares Procrustes superimposition (GLS) was applied to the coordinates of raw landmarks to scale, translate and rotate and get new shape variables independent of the scale size (Rohlf, 1990). A regression analysis was performed 
between the logarithm of centroid sizes and Procrustes coordinates within each group to eliminate the within-group size-variances. Canonical Variates Analysis (CVA) and Discriminant Function Analysis (DFA) were performed to examine the separation of different age groups. Permutation test was performed (10 000 iterations) to assess the reliability of the results.

\section{Results}

The result of the regression analysis shows significant allometry in all age groups $(p=0.001)$. The average variance of size accounted for $3.47 \%$ of the whole shape variance. All experimental groups could be discriminated significantly from each other, except two pairs (3+-5+ and 4+-5+) (Table 2).

Table 2. Analysis of the seven age groups of gibel carp (Carassius gibelio) scale shape using geometric morphometrics. Left half-matrix: $T^{2}$ statistics; right half-matrix: p-values; diagonal in italics: average similarities in groups. The non-significant results are in bold.

\begin{tabular}{c|c|c|c|c|c|c|c}
\hline & $\mathbf{0 +}$ & $\mathbf{1 +}$ & $\mathbf{2 +}$ & $\mathbf{3 +}$ & $\mathbf{4 +}$ & $\mathbf{5 +}$ & $\mathbf{6 +}$ \\
\hline $\mathbf{0 +}$ & 0.645 & 0.027 & $<0.001$ & $<0.001$ & $<0.001$ & $<0.001$ & $<0.001$ \\
$\mathbf{1 +}$ & 32.72 & 0.636 & 0.006 & $<0.001$ & $<0.001$ & $<0.001$ & $<0.001$ \\
$\mathbf{2 +}$ & 147.29 & 42.81 & 0.498 & 0.002 & 0.02 & 0.022 & $<0.001$ \\
$\mathbf{3 +}$ & 616.94 & 135.57 & 49.56 & 0.498 & 0.049 & $\mathbf{0 . 2 0 7}$ & 0.008 \\
$\mathbf{4 +}$ & 357.96 & 147.64 & 34.81 & 28.57 & 0.373 & $\mathbf{0 . 1 4 5}$ & $<0.001$ \\
$\mathbf{5 +}$ & 340.58 & 97.12 & 33.92 & $\mathbf{1 9 . 0 6}$ & $\mathbf{2 1 . 4 7}$ & 0.458 & 0.004 \\
$\mathbf{6 +}$ & 761.58 & 214.29 & 115.26 & 40.92 & 75.64 & 46.15 & 0.484 \\
\hline
\end{tabular}

CVA analysis revealed that scale shape of younger age groups $(0+-2+)$ could be discriminated along with the first canonical axis, while older age-classes $(3+-6+)$ form an integrated group, which is only dissolved along the second canonical axis, accounted for considerably less variance (7.3\%; Fig. 3).

The classification rates proved to be high: $91.6 \pm 7.37 \%$ (mean \pm SD) (not including the non-significant groups) (Table 3).

The comparison of average scale shape of the different age groups shows that up until the $3+$ group the change in direction of shape is very similar (Fig. 4). Between the $3+$ and $4+$ groups the scales begin to widen, then the caudal edge starts to narrow and the proportion of the exposed area decreases.

Table 3. Classification rates of seven age groups of gibel carp (Carassius gibelio) scale shape: results of discriminant function analysis. Left half-matrix: cross-validation rates; right half-matrix: classification rates. The non-significant results are in bold.

\begin{tabular}{c|c|c|c|c|c|c|c}
\hline & $\mathbf{0 +}$ & $\mathbf{1 +}$ & $\mathbf{2 +}$ & $\mathbf{3 +}$ & $\mathbf{4 +}$ & $\mathbf{5 +}$ & $\mathbf{6 +}$ \\
\hline $\mathbf{0 +}$ & & $85 \%$ & $100 \%$ & $100 \%$ & $100 \%$ & $100 \%$ & $100 \%$ \\
$\mathbf{1 +}$ & $57.5 \%$ & & $87.5 \%$ & $95 \%$ & $95 \%$ & $95 \%$ & $97.5 \%$ \\
$\mathbf{2 +}$ & $92.5 \%$ & $72.5 \%$ & & $87.5 \%$ & $80 \%$ & $85 \%$ & $90 \%$ \\
$\mathbf{3 +}$ & $97.5 \%$ & $85 \%$ & $77.5 \%$ & & $77.5 \%$ & $\mathbf{7 7 . 5 \%}$ & $85 \%$ \\
$\mathbf{4 +}$ & $95 \%$ & $95 \%$ & $67.5 \%$ & $60 \%$ & & $\mathbf{8 0 \%}$ & $95 \%$ \\
$\mathbf{5 +}$ & $97.5 \%$ & $85 \%$ & $62.5 \%$ & $\mathbf{5 5 \%}$ & $\mathbf{5 5 \%}$ & & $85 \%$ \\
$\mathbf{6 +}$ & $97.5 \%$ & $97.5 \%$ & $87.5 \%$ & $67.5 \%$ & $87.5 \%$ & $70 \%$ & \\
\hline
\end{tabular}




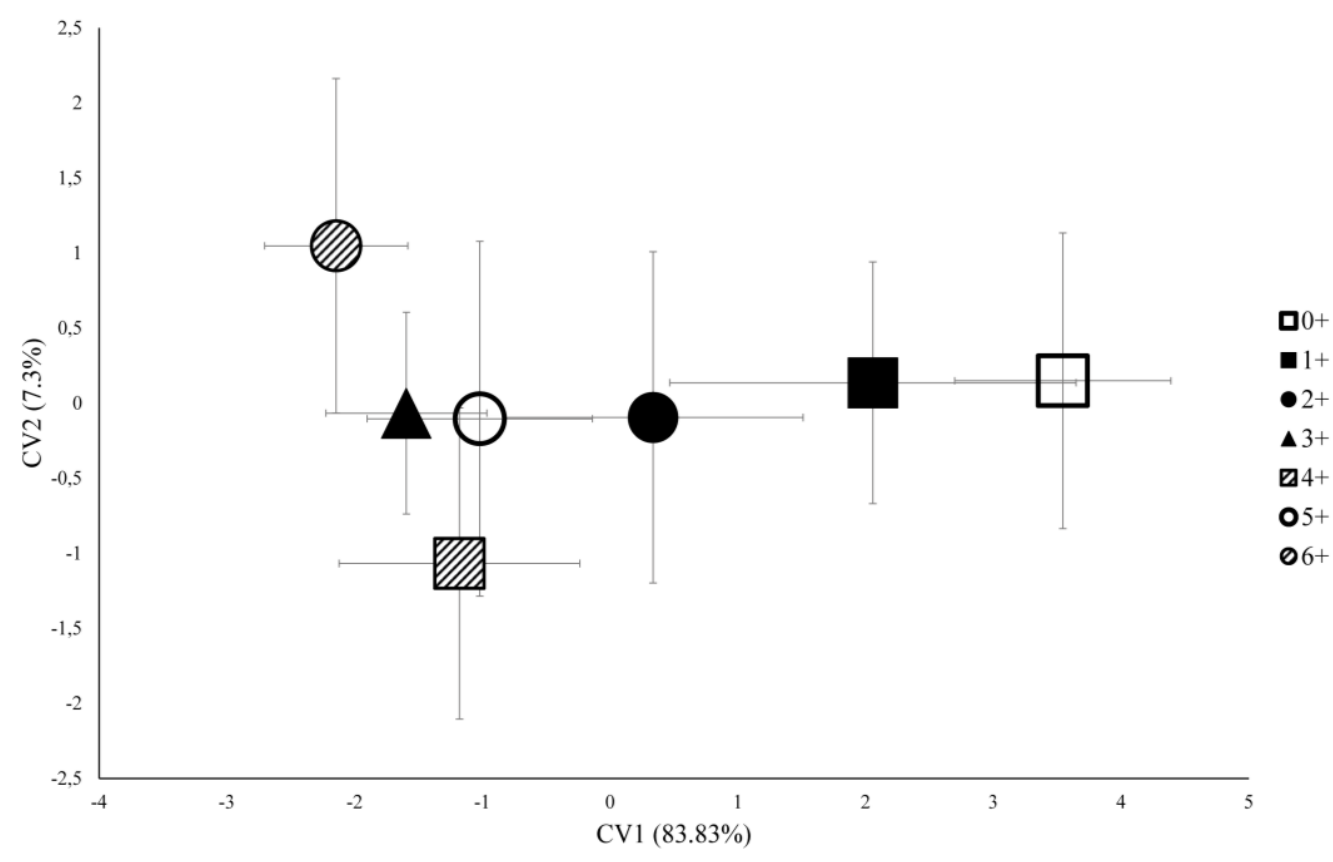

Figure 3. Differences between the seven gibel carp (Carassius gibelio) age groups based on their scales shape. Symbols shows the groups average, crosshairs shows the standard deviation, percentage values shows the carried variance proportions of the axes.

\section{anterior area}

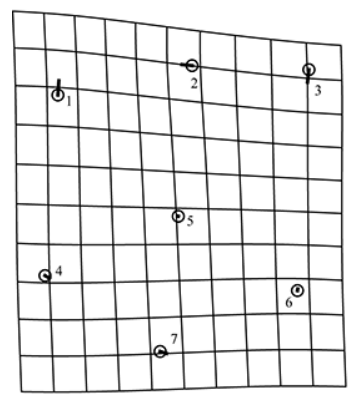

A

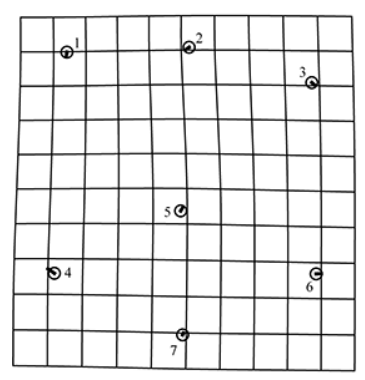

$\mathrm{D}$

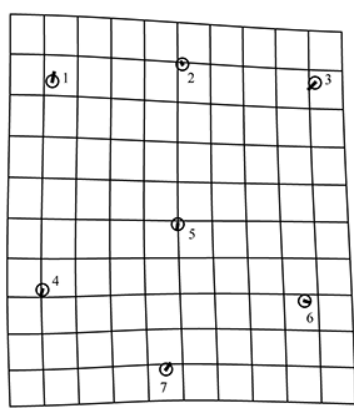

B

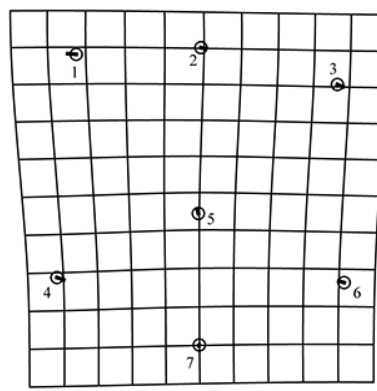

$\mathrm{E}$

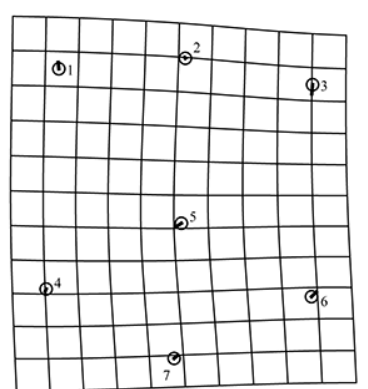

$\mathrm{C}$

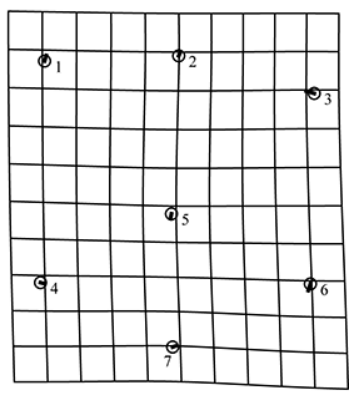

$\mathrm{F}$

posterior area

Figure 4. Differences between the gibel carp (Carassius gibelio) age groups' scales shape illustrated with thin plate spline $(A-0+-1+, B-1+-2+, C-2+-3+, D-3+-4+, E-4+-5+, F$ $-5+-6+)$ 
The experimental groups were further categorized, based on the CVA results: the former age groups were ranked into three categories, referring as "life stages" (juvenile: 0+, 1+; subadult: 2+; adult: $3+, 4+, 5+, 6+$ ) (Harka and Sallai, 2004). Another CVA was performed on the three new groups ("life stages"). Based on the results of regression analysis the size affected the shape significantly $(\mathrm{p}<0.001)$, in similar degree $(4.59 \%)$ as in age groups. All the three groups separated from each other significantly $(\mathrm{p}<0.001)$ (Table 4).

Table 4. Examination of three life stages of gibel carp (Carassius gibelio) scale shape with geometric morphometrics. Left half-matrix: $T^{2}$ statistics; right half-matrix: p-values; diagonal in italics: average similarities in groups

\begin{tabular}{c|c|c|c}
\hline & Juvenile & Subadult & Adult \\
\hline Juvenile & 0.79 & $<0.001$ & $<0.001$ \\
Subadult & 72.2 & 0.368 & $<0.001$ \\
Adult & 509.37 & 76.92 & 0.241 \\
\hline
\end{tabular}

The three groups separated from each other along the first canonical axis (Fig. 5), which is accounted for the $98 \%$ of the total variance.

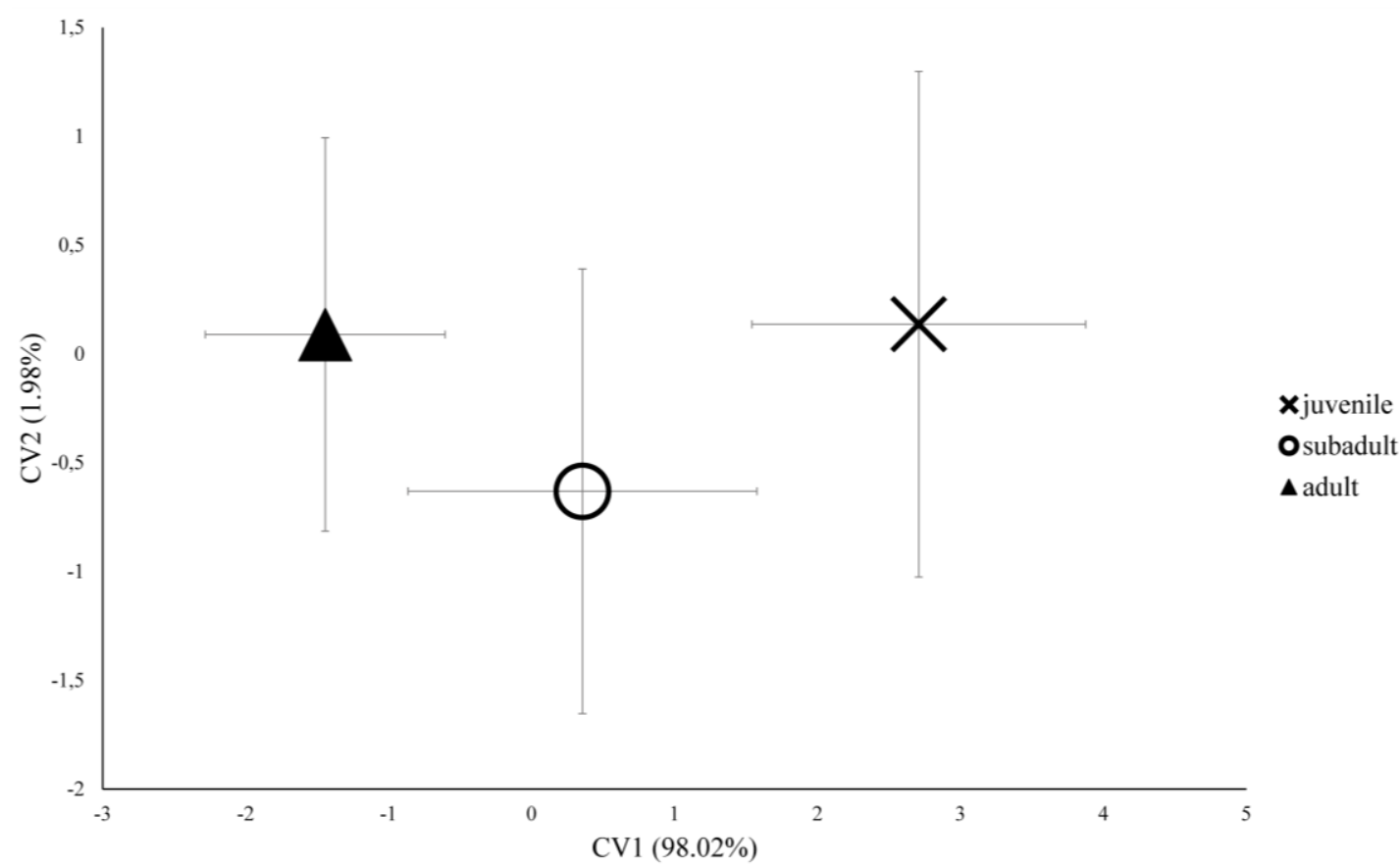

Figure 5. Separation of the gibel carp (Carassius gibelio) three life stages based on scales shape. Symbols show the groups average, crosshairs show the standard deviation, percentage values shows the carried variance proportions of the axes.

The classification rates were very similar to the analysis of the seven age groups, (mean $\pm \mathrm{SD}$ ): $89.9 \pm 3.54 \%$ (Table 5). 
Table 5. Classification rates of three life stages of gibel carp (Carassius gibelio), scale shape analyzed with discriminant function analysis. Left half-matrix: cross-validation rates; right half-matrix: classification rates.

\begin{tabular}{c|c|c|c}
\hline & Juvenile & Subadult & Adult \\
\hline Juvenile & & $88.75 \%$ & $93.75 \%$ \\
Subadult & $81.25 \%$ & & $86.90 \%$ \\
Adult & $96.90 \%$ & $76.25 \%$ & \\
\hline
\end{tabular}

\section{Discussion}

Our analyses revealed a clear trend of scale shape development in case of gibel carp, which was separated into three stages: ' $0+-1+$ ': juvenile; ' $2+$ ': subadult; ' $3+-6+$ ': adult. Microstructural, histological changes, and genetic background processes of scale development are well known during the ontogenesis of fishes (Breitler-Hahn and Zylberberg, 1993; Sire and Akimenko, 2004; Levin, 2011), however according to our knowledge no comparable data is available regarding the shape changes of other fish species. Our results suggest that however the scale itself appears in a very early life stage (e.g.: at $8 \mathrm{~mm}$ standard length in case of zebrafish (Le Guellec et al., 2004)), the shape might have its own ontogenetic development.

In the case of gibel carp, the background of scale shape changes might be related to the sexual maturity, since the time of maturation could be dated to the 3+-4+ age in Central Europe (Szczerbowski, 2001). Figure 3 shows a clear pattern with opposite shape changes amongst the groups, which is possibly in connection with maturation. In the case of young groups $(0+-3+)$, the groups follow each other step by step in a negative direction along the first canonical axis. Later the groups were separated along the second canonical axis. This phenomenon is likely in connection with the ontogenetic development of body shape, which was described in detail in several studies. In case of red-bellied piranha (Pygocentrus natterei KNER 1858) the study of Zelditch and Fink (1995) demonstrated that during the ontogenetic development the middle section of the body, the postorbital section of the head, as well as the nape area are elongating, and the whole head becomes higher. It was also reported in case of cascarudo (Callichthys callichthys L. 1758) that the body and the postorbital region elongated, the caudal peduncle became thinner and the height of abdominal region increased (Reis et al., 1998). Hood and Heins (2000) had similar findings in Blacktail shiner (Cyprinella venusta), which suggests that ontogenetic changes in reproductive status is in connection with body shape change. The results of our study coincide with these findings. As the number of scale lines are fixed along the body of the fish, after the age $3+$, the body height increased relative to body length, which cause the widening of the scales. After that, the middle section of the fish elongated (the body and the scales were growing in higher proportion to cranio-caudal direction), that is the reason of the scales narrowed in dorso-ventral direction.

\section{Conclusion}

In conclusion, the age structure of the sample may have an important role in scale shape morphometric studies. In our opinion this finding has to be taken into consideration in further comparative scale morphometric analyses, while the 
asymmetric age distributions might affect the results significantly, false population level separation could be observed without the presence of genetic and/or environmental differences. Furthermore, involvement of specimens' size as a supplementary variable in the scale morphological analyses (Ibáñez and O'Higgins, 2008) became questionable, since length is strongly correlated with the age of the fish (Le Cren, 1951). Further studies needed to test our findings on different other species and the quantified effect of the asymmetric age distribution of the compared groups.

Acknowledgements. This study was supported by the NVKP_16-2016-1-0003: Risks of some endocrine disruptors and developments for risk mitigation in Budapest Metropolitan Region project, financed by the NRDI Fund. Árpád Ferincz, Péter Takács and Ádám Staszny were supported by the Bolyai Fellowship of the Hungarian Academy of Sciences and the Ministry of Human Capacities ÚNKP-18-4-SZIE New National Excellence Program. Gábor Paulovits and Péter Takács were supported by the GINOP 2.3.2 - 15 - 2016 - 00004 project: Establishing the sustainable angling-aimed management of Lake Balaton. The publication is supported by the EFOP-3.6.3-VEKOP-16-2017-00008 project. The project is co-financed by the European Union and the European Social Fund.

\section{REFERENCES}

[1] Albertson, R. C.; Kawasaki, K. C., Tetrault, E. R, Powder, K. E. (2018): Genetic analyses in Lake Malawi cichlids identify new roles for Fgf signaling in scale shape variation. Com Biol 1: 1-11.

[2] Avigliano, E., Domanicoc, A., Sánchez, S., Volpedoa, A. V. (2017): Otolith elemental fingerprint and scale and otolith morphometry in Prochilodus lineatus provide identification of natal nurseries. - Fish Res 186: 1-10.

[3] Bräger, Zs., Gonzalvo, J., Agazzi, S., Bearzi, G. (2016): Identification of bottlenose dolphin (Tursiops truncatus) prey using fish scale analysis. - Aquat Mamm Moline 42: 63-73.

[4] Breitler-Hahn, J., Zylberberg, L. (1993): Regeneration of teleost fish scale. - Comp Biochem Physiol A Physiol 105(4): 625-641.

[5] Garduño-Paz, M. V., Demetriou, M., Adams, C. E. (2010): Variation in scale shape among alternative sympatric phenotypes of Arctic charr Salvelinus alpinus from two lakes in Scotland. - J Fish Biol 76: 1491-1497.

[6] Gayzik, F. S., Yu, M. M., Danelson, K. A., Slice, D. E., Stitzel, J. D. (2008): Quantification of age-related shape change of the human rib cage through geometric morphometrics. - J Biomech 41: 1545-1554.

[7] Harka, Á., Sallai, Z. (2004): Magyarország halfaunája. - Nimfea Természetvédelmi Egyesület, Szarvas (in Hungarian).

[8] Hood, C. S., Heins, D. C. (2000): Ontogeny and allometry of body shape in the blacktail shiner, Cyprinella venusta. - Copeia 1: 270-275.

[9] Ibáñez, A. L. (2015): Fish traceability: guessing the origin of fish from a seafood market using fish scale shape. - Fish Res 170: 82-88.

[10] Ibáñez, A. L., O'Higgins, P. (2008): Identifying fish scales: the influence of allometry on scale shape and classification. - Fish Res 109(1): 54-60.

[11] Ibáñez, A. L., Jawad, L. A. (2018): Morphometric variation of fish scales among some species of rattail fish from New Zealand waters. - J Mar Biol Assoc UK 98(8): 19911998.

[12] Ibáñez, A. L., Cowx, I. G., O’Higgins, P. (2007): Geometric morphometric analysis of fish scales for identifying genera, species, and local populations within the Mugilidae. Can J Fish Aquat Sci 64: 1091-1100. 
[13] Ibáñez, A. L., Pacheco-Almanzar, E., Cowx, I. G. (2012): Does compensatory growth modify fish scale shape? - Environ Biol Fish 94(2): 477-482.

[14] Klingenberg, C. P. (2011): MorphoJ: an integrated software package for geometric morphometrics. - Mol Ecol Resour 11: 353-357.

[15] Le Cren, E. D. (1951): The length-weight relationship and seasonal cycle in gonad weight and condition in the perch (Perca fluviatilis). - J Anim Ecol 20(2): 201-219.

[16] Le Guellec, D., Morvan-Dubois, G., Sire, J.-Y. (2004): Skin development in bony fish with particular emphasis on collagen deposition in the dermis of the zebrafish (Danio rerio). - Int J Dev Biol 48: 217-231.

[17] Levin, B. A. (2011): Ontogenetic causes and mechanisms for formation of differences in number of fish scales. - Russ J Dev Biol 42(3): 186-191.

[18] Pérez-Tris, J., Tellería, J. L. (2001): Age-related variation in wing shape of migratory and sedentary Blackcaps Sylvia atricapilla. - J Avian Biol 32: 207-213.

[19] Pompei, L., Carosi, A., Pedicillo, G., Rocchini, E., Lorenzoni, M. (2011): Age and growth analysis of the chub, Squalius squalus (Bonaparte, 1837), in the Assino Creek (Umbria, Italy). - Knowl Manag Aquat Ecosyst 400: 09.

[20] Reis, R. E., Zelditch, M. L., Fink, W. L. (1998): Ontogenetic allometry of body shape in the neotropical catfish Callichthys (Teleostei: Siluriformes). - Copeia 1998: 177-182.

[21] Rohlf, F. J. (1990): Morphometrics. - Ann Rev Ecol Syst 21: 299-316.

[22] Rohlf, F. J. (2005): tpsDig, Digitize Landmarks and Outlines, Version 2.31. - Department of Ecology and Evolution, State University of New York at Stony Brook. http://life.bio.sunysb.edu/morph/morphmet/tpsdig2w32.exe (accessed 8 February 2018).

[23] Rohlf, F. J. (2015): tpsUtil, File Utility Program. Version 1.75. - Department of Ecology and Evolution, State University of New York at Stony Brook. http://life.bio.sunysb.edu/morph/morphmet/tpsutilw64.exe (accessed 8 February 2018).

[24] Şerban, C., Grigoraş, G. (2018): Structural and morphometric study of scales in Petzea rudd (Scardinius racovitzai Müller 1958). - Appl Ecol Env Res 16(5): 6063-6076.

[25] Sheridan, L., Pomiankowski, A. (1997): Fluctuating asymmetry, spot asymmetry and inbreeding depression in the sexual coloration of male guppy fish. - Heredity 79: 515523.

[26] Sire, J. Y., Akimenko, M. A. (2004): Scale development in fish: a review, with description of sonic hedgehog (shh) expression in the zebrafish (Danio rerio). - Int J Dev Biol 48: 233-247.

[27] Soriguer, M. C., Vallespín, C., Gomez-Cama, C., Hernando, J. A. (2000): Age, diet, growth and reproduction of a population of Cobitis paludica (de Buen, 1930) in the Palancar Stream (southwest of Europe, Spain) (Pisces: Cobitidae). - Hydrobiol 436: 5158.

[28] Staszny, Á., Ferincz, Á., Weiperth, A., Havas, E., Urbányi, B., Paulovits, G. (2012): Scale-morphometry study to discriminate Gibel carp (Carassius gibelio) populations in the Balaton-Catchment (Hungary). - Acta Zool Acad Sci Hun 58(Suppl.): 19-27.

[29] Staszny, Á., Havas, E., Kovács, R., Urbányi, B., Paulovits, G., Bencsik, D., Ferincz, Á., Müller, T., Specziár, A., Bakos, K., Csenki, Z. (2013): Impact of environmental and genetic factors on the scale shape of zebrafish, Danio rerio (Hamilton 1822): a geometric morphometric study. - Acta Biol Hun 64: 462-475.

[30] Szczerbowski, J. A. (2001): Carassius Jarocki, 1822. - In: Bănărescu, P. M., Paepke, H. J. (eds.) The Freshwater Fishes of Europe. Vol. 5. Cyprinidae 2. Part 3. Carassius to Cyprinus. Gasterosteidae. Aula-Verlag, Wiebelsheim, Germany, pp. 1-78.

[31] Takács, P., Vitál, Z., Ferincz, Á., Staszny, Á. (2016) Repeatability, reproducibility, separative power and subjectivity of different fish morphometric analysis methods. PLoS One 11(6): e0157890.

[32] Wimberger, P. H. (1992) Plasticity of fish body shape. The effects of diet, development, family and age in two species of Geophugus (Pisces: Cichlidae). - Biological Journal of the Linnean Society 45: 197-218. 
[33] Zelditch, M. L., Fink, W. L. (1995): Allometry and developmental integration of body growth in a piranha, Pygocentrus nattereri (Teleostei: Ostariophysi). - Journal of Morphology 223: 341-355.

[34] Zelditch, M. L., Swiderski, D. L., Sheets, H. D., Fink, W. L. (2004): Geometric morphometrics for biologists: A primer. - Elsevier Academic Press, New York. 